\title{
Дополнительные сведения о наземных водорослях горного Алтая (Республика Алтай, Россия)
}

\section{Additional information about terrestrial algae of the Altai Mountains (Altai Republic, Russia)}

\author{
Егорова И. Н., Шамбуева Г. С., Морозова Т. И. \\ Egorova I. N., Schambuyeva G. S., Morozova T. I. \\ Сибирский институт физиологии и биохимии растений СО РАН, г. Иркутск, Россия. \\ E-mail:egorova@sifibr.irk.ru,galina93shambueva@mail.ru,ti.morozova@mail.ru
}

Siberian Institute of Plant Physiology and Biochemistry, Siberian Branch of the Russian Academy of Sciences, Irkutsk, Russia

Peферат. Рассмотрена история изучения водорослей в наземных местообитаниях горного Алтая. В результате экспедиционных работ на территории региона, и лабораторных исследований, авторами выявлен 21 вид водорослей, населяющих почву и различные наземные субстраты (каменистые и растительные). Установлены новые местонахождения ряда представителей. Общий список наземных водорослей горного Алтая в пределах Республики Алтай, составленный по собственным и опубликованным данным, насчитывает 73 видовых и внутривидовых таксона.

Ключевые слова. Биоразнообразие, горный Алтай, наземные водоросли.

Summary. The history of the study of terrestrial algae of the Altai Mountains is considered. The authors identified 21 species of algae that inhabit the soil and various ground substrates (rocky and plant). New locations of a number of representatives have been established. The General list of terrestrial algae of the Altai Mountains within the Altai Republic, compiled from its own and published data, has 73 species and intraspecific taxa.

Key words. Altai Mountains, biodiversity, terrestrial algae.

В данной работе рассматривается система гор, принадлежащих Алтаю, в пределах Республики Алтай. До настоящего времени эта территория остается слабо изученной в отношении наземных водорослей - группы первичных продуцентов, играющих значительную роль в функционировании биогеоценозов. Одно из первых сообщений об этих организмах принадлежит C. G. Ehrenberg, который в летнем снегу альпийской возвышенности Проходной вблизи г. Риддер (современный Казахстан) отметил диатомовую водоросль Fragilaria pectinalis (O. F. Müller) Lyngbye (цит. по Миддендорф, 1867). Известный исследователь Б. А. Келлер отмечал распространенность в среднеазиатских степях вплоть до предгорий Алтая представителя цианопрокариот (Суanoprokaryota) Nostoc commune Vaucher ex Bornet et Flahault (Келлер, 1926). В 1929 г. В. И. Барановым в высокогорьях юго-восточного Алтая вблизи озера Богуты (Кош-Агачский район Республики Алтай) было обнаружено массовое развитие макроскопических водорослей и коллекционированы образцы. А. А. Еленкин установил, что собранный В. И. Барановым материал - это Nostoc commune (Stratonostoc commune (Vaucher) Elenkin), и отметил специфичность изученного материала (Еленкин, 1931, 1938). В 1970 г. Ж. Ф. Пивоварова исследовала почвенные водоросли в окрестностях пос. Кош-Агач. В результате ею был опубликован список найденных представителей, включающий 42 таксона видового и внутривидового ранга из отделов Суanoprokaryota, Xanthophyta (желтозеленые), Chlorophyta (зеленые), Euglenophyta (эвгленовые) (Пивоварова, 1974). Впоследствии работы по изучению почвенных водорослей гор Алтая были ею продолжены. Они включали исследования в Курайской и Чуйской степях (Кош-Агачский р-он), а также в Прителецкой части Алтайского государственного заповедника (Пивоварова и др., 2008). Отмечалось о нахождении 58 ви- 
дов и подвидов водорослей в почвах Чуйской степи, 85 видовых и внутривидовых таксонов - в почвах Курайской степи и 139 представителей почвенных водорослей на исследуемой территории Алтайского заповедника. К сожалению, список найденных видов не опубликован. В 2002 и 2003 гг. в ходе исследований на леднике Аккем (Усть-Коксинский р-он Республики Алтай) в снежном покрове были выявлены 5 представителей цианопрокариот, зеленых и стрептофитовых (Streptophyta) водорослей (Takeushi et al., 2006). В исследованиях комплекса микроорганизмов почв в корнеобитаемом слое жимолости алтайской, проведенных на склонах Молниебойного хребтика (Усть-Коксинский р-он) и горного поднятия Ак-Туру (Кош-Агачский р-он), отмечалось наличие здесь цианопрокариот, в том числе водорослей Nostoc Vaucher ex Bornet et Flahault (Артамонова и др., 2010). В 2012 г. были проведены исследования водорослей пещер Кёк-Таш (Шебалинский р-он Республики Алтай), Большая Талдинская (Майминский район Республики Алтай) и Нижняя Иогачская (Турочакский р-он Республики Алтай), которые включали изучение водорослей грунта, стен пещер и воды (Абдуллин, Гайнутдинов, 2014). Выявлено 23 вида цианопрокариот, диатомовых (Bacillariophyta) и зеленых водорослей, 10 видов из числа найденных приведено в работе.

По имеющимся опубликованным данным нами составлен список видов водорослей горного Алтая, который содержит 57 видовых и внутривидовых таксонов из отделов Cyanoprokaryota, Bacillariophyta, Xanthophyta, Euglenophyta, Chlorophyta, Streptophyta. Система отделов принята в соответствии с работой Н. П. Масюк, И. Ю. Костиков (2002).

В 2015 г. авторами были проведены изыскания в Кош-Агачском районе в окрестностях Богутинских озер, целью которых было исследование этих мест на предмет наличия Nostoc commune. Вид, как отмечалось выше, был обнаружен здесь в 1929 г. и больше никем местонахождение не изучалось. В ходе работ нами было повторно обследована данная территория, выявлено массовое развитие вида, коллекционированы образцы водоросли, также собраны почвенно-альгологические пробы и образцы различных наземных субстратов в окрестностях оз. Большое Богуты, пос. Кош-Агач и в нескольких местах по ходу Чуйского тракта. Обработка материала проведена методами, ранее неоднократно опубликованными (Егорова, 2016; Egorova et al., 2018 и др.). Ниже приведен список водорослей, составленный по опубликованным и собственным, не публиковавшимся данным. В отделах роды и виды внутри родов приведены в алфавитном порядке в соответствии с современной номенклатурой (Guiry, Guiry, 2019). Для ряда представителей даны названия, под которыми их указывали в публикациях. Для каждого вида также приводится район, где его находили; субстрат; ссылка на источник информации.

\section{Cyanoprokaryota}

1. Anagnostidinema acutissimum (Kufferath) Strunecký, Bohunická, Johansen et Komárek (как Oscillatoria acutissima Kufferath) - Кош-Агачский р-он. Почва (Пивоварова, 1974).

2. Aphanocapsa muscicola (Meneghini) Wille - Кош-Агачский р-он. Почва (авторские данные).

3. Calothrix parietina Thuret - Усть-Коксинский p-он. Ледник Аккем (Takeushi et al., 2006).

4. Calothrix sp. - Кош-Агачский р-он. Почва (авторские данные).

5. Coleofasciculus chthonoplastes (Thuret ex Gomont) M. Siegesmund, J. R. Johansen et T. Friedl (как Microcoleus chtonoplastes (Flora Danica) Thuret) - Кош-Агачский р-он. Почва (Пивоварова, 1974).

6. Leptolyngbya amplivaginata (Van Goor) Anagnostidis et Komárek (как Lyngbya amplivaginata Van Coor) - Кош-Агачский р-он. Почва (Пивоварова, 1974).

7. L. angustissima (West et G. S. West) Anagnostidis et Komárek (как Phormidium angustissimum W. et G. S. West) - Кош-Агачский р-он. Почва (Пивоварова, 1974).

8. L. boryana (Gomont) Anagnostidis et Komárek - Шебалинский, Турочакский р-оны. Пещеры (Абдуллин, Гайнутдинов, 2014).

9. L. foveolara (Rabenhorst ex Gomont) Anagnostidis et Komárek (как Phormidium foveolarum (C. Montagne) Gomont) - Кош-Агачский р-он. Почва (Пивоварова, 1974; авторские данные).

10. L. halophila (Hansgirg) Anagnostidis et Komárek (как Lyngbya halophyla Hansgirg) - Кош-Агачский р-он. Почва (Пивоварова, 1974).

11. L. tenuis (Meneghini ex Gomont) Anagnostidis et Komárek (как Phormidium tenue (Meneghini) Gomont) - Кош-Агачский р-он. Почва (Пивоварова, 1974). 
12. Leptolyngbya sp. - на поверхности колоний N. commune (авторские данные).

13. Microcoleus amoenus (Gomont) Strunecky, Komárek et J.R.Johansen (как Oscillatoria amoena (Kützing) Gomont) - Кош-Агачский р-он. Почва (Пивоварова, 1974).

14. M. autumnalis (Gomont) Strunecky, Komárek et J. R. Johansen (как Phormidium autumnale (C. Agardh) Gomont) - Кош-Агачский р-он. Почва (Пивоварова, 1974).

15. M. subtorulosus Gomont ex Gomont (как Microcoleus subtorulosus (Brebisson) Gomont) - Кош-Агачский р-он. Почва (Пивоварова, 1974).

16. Nostoc commune Vaucher ex Bornet et Flahault - Кош-Агачский р-он. Почва (Еленкин, 1931, 1938; авторские данные); Чемальский, Онгудайский, Шебалинский р-оны, поверхность почвы и камней (авторские данные).

17. N. paludosum Kützing ex Bornet et Flahault - Турочакский р-он. Пещеры (Абдуллин, Гайнутдинов, 2014).

18. N. punctiforme (Kützing ex Hariot) Hariot - Турочакский р-он. Пещеры (Абдуллин, Гайнутдинов, 2014), Кош-Агачский р-он. Почва (авторские данные).

19. N. punctiforme f. populorum (Geitler) Hollerbach (как Amorphonostoc punctiforme f. populorum (Geitler) Hollerbach) - Кош-Агачский р-он. Почва (Пивоварова, 1974).

20. Oscillatoria limnetica Lemmermann f. acicularis (Nygaard) V. Poljansky - Кош-Агачский р-он. Почва (Пивоварова, 1974).

21. Oscillatoriaceae cyanobacteria - Усть-Коксинский р-он. Ледник Аккем (Takeushi et al., 2006).

22. Phormidesmis molle (Gomont) Turicchia, Ventura, Komárková et Komárek (как Phormidium molle (Kützing) Gomont) - Кош-Агачский р-он. Почва (Пивоварова, 1974).

23. Phormidium ambiquum Gomont - Кош-Агачский р-он. Почва (Пивоварова, 1974).

24. P. calcicola Gardner - Кош-Агачский р-он. Почва (Пивоварова, 1974).

25. P. corium Gomont ex Gomont (как Phormidium corium (C. Agardh) Gomont) - Кош-Агачский р-он. Почва (Пивоварова, 1974).

26. P. schroeteri (Hansgirg) Anagnostidis (как Oscillatoria brevis (Kützing) Gomont) - Кош-Агачский р-он. Почва (Пивоварова, 1974).

27. Porphyrosiphon martensianus (Meneghini ex Gomont) Anagnostidis et Komárek (как Lyngbya martensiana Meneghini) - Кош-Агачский р-он. Почва (Пивоварова, 1974).

28. Schizothrix vaginata Gomont (как Schizothrix vaginata (Nägeli) Gomont) - Кош-Агачский р-он. Почва (Пивоварова, 1974).

29. Stigonema informe Kützing ex Bornet et Flahault - Майминский р-он. На камнях в сосновом лесу (авторские данные).

30. Symplocastrum friesii (Gomont) Kirchner (как Schizothrix friesii (C. Agardh) Gomont) - Кош-Агачский р-он. Почва (Пивоварова, 1974).

31. Synechococcus elongatus (Nägeli) Nägeli (как Synechococcus elongatus Nägeli) - Кош-Агачский р-он. Почва (Пивоварова, 1974).

32. Synechocystis aquatilis Sauvageau - Кош-Агачский р-он. Почва (Пивоварова, 1974).

33. Tolypothrix tenuis Kützing ex Bornet et Flahault (как Tolypothrix tenuis Kützing) - Кош-Агачский р-он. Почва (Пивоварова, 1974).

34. Trichormus variabilis (Kützing ex Bornet et Flahault) Komárek et Anagnostidis - Шебалинский р-он. Пещеры (Абдуллин, Гайнутдинов, 2014).

\section{Bacillariophyta}

35. Nitzschia palea (Kützing) W. Smith - Шебалинский р-он. Пещеры (Абдуллин, Гайнутдинов, 2014).

36. Achnanthidium lineare W. Smith (как Rossithidium linearis (W. Smith) Round et Bukhtiyarova) - Шебалинский р-он. Пещеры (Абдуллин, Гайнутдинов, 2014).

\section{Xanthophyta}

37. Characiopsis minima Pascher - Кош-Агачский р-он Почва (Пивоварова, 1974).

38. Ellipsoidion simplex Pascher - Кош-Агачский р-он. Почва (Пивоварова, 1974). 
39. Ellipsoidion stichoccoides Pascher - Кош-Агачский р-он. Почва (Пивоварова, 1974).

40. Gloeobotrys chlorinus Pascher - Кош-Агачский р-он. Почва (Пивоварова, 1974).

41. Heterogloea minor Pascher - Кош-Агачский р-он. Почва (Пивоварова, 1974).

42. Monodus chodatii Pascher - Кош-Агачский р-он. Почва (Пивоварова, 1974).

43. Pleurochloris commutata Pascher - Кош-Агачский р-он. Почва (Пивоварова, 1974).

44. Vaucheria terrestris (Vaucher) De Candolle - Кош-Агачский р-он. Почва (Пивоварова, 1974).

\section{Eustigmatophyta}

45. Vischeria magna (Petersen) Kryvenda, Rybalka, Wolf et Friedl - Кош-Агачский р-он. Почва, на поверхности колоний $N$. соттипе (авторские данные).

\section{Chlorophyta}

46. Bracteacoccus sp. - Кош-Агачский р-он. Почва, на поверхности колоний $N$. coтmune (авторские данные).

47. Chlamydomonas sp. - Кош-Агачский р-он. Почва (Пивоварова, 1974).

48. Cf. Chlamydomonas - Кош-Агачский р-он. Почва (авторские данные).

49. Chlorella vulgaris Beyerinck - Кош-Агачский р-он. Почва (Пивоварова, 1974).

50. Chlorella-like alga 1 - Кош-Агачский р-он. На поверхности колоний $N$. соттипе (авторские данные).

51. Chlorella-like alga 2 - Кош-Агачский р-он. Почва (авторские данные).

52. Chlorococcum ellipsoideum Deason et Bold - Турочакский р-он. Пещеры (Абдуллин, Гайнутдинов, 2014).

53. Chlorococcum humicola (Nägeli) Rabenhorst (как Chlorococcum humicola Raff.) - Кош-Агачский p-он. Почва (Пивоварова, 1974).

54. Chlorococcum minutum Starr - Шебалинский p-он. Пещеры (Абдуллин, Гайнутдинов, 2014).

55. Chloromonas sp. - Усть-Коксинский р-он. Ледник Аккем (Takeuchi et al., 2006).

56. Choricystis chodatii (Jaag) Fott - Шебалинский р-он. Пещеры (Абдуллин, Гайнутдинов, 2014).

57. Coelastrella sp. - Кош-Агачский р-он. Почва (авторские данные).

58. Diplosphaera chodatii Bialosukniá - Кош-Агачский р-он. Почва (авторские данные).

59. Eubrownia aggregata (R.M.Brown et Bold) S. Watanabe et L.A.Lewis - Кош-Агачский р-он. Почва (авторские данные).

60. Fottea stichoccoides Hindák- Кош-Агачский р-он. На поверхности колоний N. commune (авторские данные).

61. Mychonastes homosphaera (Skuja) Kalina et Punčochárová - Шебалинский, Турочакский, Майминский р-оны. Пещеры (Абдуллин, Гайнутдинов, 2014).

62. Neocystis sp. - Кош-Агачский р-он. На поверхности колоний N. соттипе (авторские данные).

63. Oocystis sp. - Кош-Агачский р-он. Почва (Пивоварова, 1974).

64. Palmellopsis sp. - Кош-Агачский р-он. Почва (авторские данные).

65. Parietochloris cf. cohaerens (Groover et Bold) S. Watanabe et Floyd - Кош-Агачский р-он. Почва (авторские данные).

66. Pleurastrum sp. - Кош-Агачский р-он. Почва (авторские данные).

67. Spongiochloris sp. - Кош-Агачский р-он. Почва (авторские данные).

68. Stichococcus bacillaris Nägeli - Кош-Агачский р-он. Почва (Пивоварова, 1974).

69. Trentepohlia sp. - Кош-Агачский р-он. почва (Пивоварова, 1974).

\section{Streptophyta}

70. Ancylonema nordenskioeldii Berggren - Усть-Коксинский р-он. Ледник Аккем (Takeuchi et al., 2006).

71. Mesotaenium berggrenii (Wittrock) Lagerheim - Усть-Коксинский р-он. Ледник Аккем (Takeuchi et al., 2006)

72. Klebsormidium sp. - Кош-Агачский р-он. Почва, на поверхности колоний $N$. соттипе (авторские данные). 


\section{Euglenophyta}

73. Euglena sp. - Кош-Агачский р-он. Почва (Пивоварова, 1974).

Ряд выявленных нами представителей не идентифицированы до вида или рода. Их идентификация требует использования методов высокоразрешающей микроскопии и молекулярной филогении. С этой целью получены альгологически чистые культуры (в частности, культуры Chlorella-подобных водорослей), которые поддерживаются в коллекции культур водорослей IRK-A.

Благодарности. Авторы выражают глубокую признательность сотрудникам Сайлюгемского национального парка за помощь в проведении экспедиционных работ. Работа выполнена при финансовой поддержке РФФИ 12-04-01365-а, а также в рамках Гос. задания 52.1.10.

\section{ЛИТЕРАТУРА}

Абдуллин Ш. Р., Гайнутдинов И. А. Биоразнообразие цианопрокариот и водорослей некоторых пещер Республики Алтай // Спелеология и спелестология: Сборник материалов V Междунар. научн. заочной конф. (К 100-летию А. В. Рюмина) (29 ноября 2014 г.). - Набережные Челны: НИСПТР, 2014. - С. 297-299.

Артамонова В. С., Булгакова В. В., Худяев С. . Микробиологическая характеристика редких почв в горах Алтая // Антропогенная трансформация природной среды, 2010. - Т. 1, № 1. - С. 113-120.

Егорова И. Н. О водорослях скально-каменистых субстратов некоторых горных районов России и Монголии // Известия Самарского научного центра РАН, 2016. - Т. 5, № 2. - С. 257-263.

Еленкин А. А. О некоторых съедобных пресноводных водорослях // Природа, 1931. - № 10. - С. 965-992.

Еленкин А. А. Сине-зеленые водоросли СССР. Вып. І. Специальная часть. - М.-Л., 1938. - 984 с.

Келлер Б. $\boldsymbol{A}$. Растительный мир русских степей, полупустынь и пустынь. Вып. 2. Низшие растения на зональных почвах и столбчатых солонцах в полупустыне. - Воронеж, 1926. - 16 с.

Масюк Н. П., Костіков І. Ю. Водорості в системі органічного світу. - Київ, 2002. - 178 с.

Миддендорф A. Ф. Путешествие на север и восток Сибири. Растительность Сибири. - СПб., 1867. - Ч. 1, Отд. 4. - C. 69(XLIX)-54(LIV).

Пивоварова Ж. Ф. Сравнительная характеристика альгосинузий под некоторыми растениями горных степей Иссык-кульской котловины Тянь-Шаня и юго-восточного Алтая // Известия Сибирского отделения Академии наук СССР. Серия биологических наук, 1974. - № 1. - С. 25-32.

Пивоварова Ж. Ф., Факторович Л. В., Круне Т. И. Почвенные водоросли горного Алтая // Фундаментальные и прикладные проблемы ботаники в начале XXI века. Материалы Всеросс. конф. Часть 2: Альгология. Микология. Лихенология. Бриология. - Петрозаводск, 2008. - С. 71-73.

Egorova I. N., Mincheva E. V., Boldina O. N. Ataktogamous green microalgae of the genus Chlorosarcinopsis Herndon (Chlorophyceae, Chlorophyta) from Zabaikalskiy region (Russia) // Phytotaxa, 2018. - Vol. 343(№ 1). - P. 001-019.

Guiry M. D., Guiry G. M. AlgaeBase. World-wide electronic publication, National University of Ireland, Galway, 2018. URL: http://www.algaebase.org (Accessed 14-17 March 2019).

Takeuchi N., Uetake Ju., Fujita K., Aizen V. B., Nikitin S. D. A snow algal community on Akkem glacier in the Russian Altai mountains // Annals of Glaciology, 2006. - № 43. - P. 378-384. 